\title{
Morphology, Dynamical Mechanical and Flame Retardant Properties of Nylon 1212/Organic Montmorillonite Nanocomposites Prepared by Melt Compounding
}

\author{
Anrong Huang, Jing Sun*, Shanshan Luo, Heng Luo \\ Guizhou Material Industrial Technology Institute, Guiyang 550014, China
}

Funding: This work was supported by the Guizhou Provincial Science and Technology Project (Qian Ke He Zhi Cheng [2019]2849, [2019]2028), and Guiyang Baiyun District Science and Technology Plan Project Grant no. [2018]5).

\begin{abstract}
Nylon 1212/organic montmorillonite (OMMT) nanocomposites were prepared using the melt compounding method. The morphology and dynamical mechanical properties of the nanocomposites were investigated using transmission electron microscope (TEM) and dynamic mechanical analysis (DMA). The storage modulus of nylon 1212/OMMT nanocomposites was increased with increasing OMMT. The flame retardant properties were characterized by cone calorimetry, scanning electron microscope (SEM) and X-ray photoelectron spectroscopy (XPS). The flame retardant properties were characterized using cone calorimetry, whereby nylon 1212/OMMT nanocomposites were improved compared with pure nylon 1212 because of the carbonaceous-silicate granular materials which were formed during combustion, thus proposing the flame retardant mechanism.
\end{abstract}

Keywords: Mechanical properties; Nanocomposites; Nylon; Polymer processing

Publication date: March, 2021; Publication online: 31 March, 2021

*Corresponding author: Jing Sun, jsz00521@163.com

\section{Introduction}

In the past decade polymer/montmorillonite nanocomposites have attracted great interest from academic and industrial researchers due to the nanosized montmorillonite (MMT) being able to greatly improve the thermal and mechanical properties $^{[1-7]}$. The introduction of nanosized clay can accelerate the crystallization rate of crystallizable polymers, with the clay layers acting as nucleating agents ${ }^{[8]}$. Wu et al. (2002) showed Nylon 1212 exhibited heterogeneous nucleation in the presence of MMT and an increased crystallization rate $^{[9]}$. However, pure Nylon 1212 crystallized as spherulites, where the spherulites of the nanocomposite were finely formed small or homogeneous size because it nucleated as it grew on the surface of the silicate layers. Since the mobility of the macromolecule chains are restricted by adding nanosized fillers, thus the glass transition temperature $\left(\mathrm{T}_{\mathrm{g}}\right)$ of the polymer will change. Dynamic mechanical analysis is an important method to characterize the glass transition. Yu et al. (2004) employed dynamic mechanical analysis to study the $\mathrm{T}_{\mathrm{g}}$ of nylon 66/MMT nanocomposites ${ }^{[10]}$. The results showed that $\mathrm{T}_{\mathrm{g}}$ of the nylon 66/MMT nanocomposites shifted to a higher temperature with increasing of the nanosized MMT contents compared to pure nylon $66^{[10]}$. Some researchers have reported that some polymers showed two $\mathrm{T}_{\mathrm{g}}$ when tested using dynamic mechanical analysis (DMA) due to the mobility of the macromolecule chain segments being restricted by the nanosized fillers ${ }^{[11-13]}$. The movement of some of the macromolecule chain segments will begin at the normal $\mathrm{T}_{\mathrm{g}}$ temperature, while the restricted parts will begin moving at a higher temperature. 
The flame retardant properties of the polymers can be improved by adding MMT. Wang et al. (2002) confirmed that the barrier properties of the MMT provided a mechanism by which nanocomposite formation can enhance the fire retardance of the polymers ${ }^{[14]}$. Wang et al. (2004) studied that when comparing the flame retardance of ABS/MMT nanocomposites with MMT nanocomposites showed lower heat release rate (HRR) peak and higher limiting oxygen index (LOI) than that of conventional flame retardant $\mathrm{ABS}^{[15]}$. Kashiwagi et al. (2004) reported that the PA6/clay nanocomposite samples (clay contents of 2 and 5\% by mass with $8 \mathrm{~mm}$ thickness) significantly reduced the HRR peak of the PA6 sample ${ }^{[16]}$.

Nylon 1212 is one of the most important semicrystalline engineering plastics in the family of nylons. It has superior physical and chemical properties compared to polyolefin plastics ${ }^{[17]}$. So far, there are limited reports about Nylon 1212/MMT nanocomposites in our research ${ }^{[18-19]}$.

In the present study we prepared nylon 1212/organic montmorillonite (OMMT) nanocomposites using melt compounding method. Transmission electron microscopy (TEM) was employed to characterize the morphology of the nylon 1212/OMMT nanocomposites. The effect of OMMT on $\mathrm{T}_{\mathrm{g}}$ of nylon 1212 was characterized by DMA. The thermo-stabilities of nylon 1212 and nylon 1212/OMMT samples were determined using thermogravimetric analysis (TGA). The flame retardant properties of the nylon 1212 and nylon 1212/OMMT nanocomposites were characterized using cone calorimetry, scanning electron microscopy (SEM) and X-ray photoelectron spectroscopy (XPS).

\section{Materials}

\subsection{Experimental materials utilized}

Nylon 1212, with a melting index of $14 \mathrm{~g} / 10 \mathrm{~min}$ $\left(230^{\circ} \mathrm{C}, 2.16 \mathrm{~kg}\right)$ was supplied by ShanDong DongChen Engineering Plastic Co., Ltd., China. The clay used in this paper was a natural OMMT modified by cetyl dimethyl benzyl ammonium chloride (CDBAC) with a cation exchange capacity of $120 \mathrm{meq} / 100 \mathrm{~g}$, and trade name of DK3 which was obtained from Zhejiang Feng Hong Clay Co., Ltd., China. All the materials were dried in a vacuum oven at $80^{\circ} \mathrm{C}$ for $12 \mathrm{~h}$ before the melt blending.

\subsection{Preparation of nylon 1212/OMMT nanocomposites}

The nylon 1212 was blended with $0,3,5$ and $7 \mathrm{wt} \%$ OMMT via a melt compounding method using a twin-screw extruder (L/D = 40, D = 20mm, Nanjing KY Chemical Machinery Co., Ltd., China) with a screw speed of $200 \mathrm{~Hz} / \mathrm{min}$ at $190^{\circ} \mathrm{C}$, and then the extrudates were pelletized with a pelletizer. Parts of the extrudates were processed into $125 \mathrm{~mm} \times 13.0 \mathrm{~mm} \times 3.0 \mathrm{~mm}$ bars by an injection molding machine (CJ-80, Chen De Plastics Machinery Co., Ltd., China). Other parts of the extrudates were compression molded into $100 \mathrm{~mm} \times 100 \mathrm{~mm} \times 4 \mathrm{~mm}$ thick square plaques at $195^{\circ} \mathrm{C}$ and $150 \mathrm{bar}$ with the plaques cooled together with the molds in room temperature.

\section{Methods}

\subsection{Transmission electron microscopy (TEM) measurements}

The morphology of the nylon 1212/OMMT nanocomposites was observed by a JEOL 200CX (JEOL Ltd., Japan) TEM at an accelerating voltage of $120 \mathrm{kV}$. Ultra-thin sections were cut from the injection molded bars perpendicular to the flow direction under cryogenic conditions using an LKB-5 (LKB Co, Switzerland) microtome.

\subsection{Dynamic mechanical analysis (DMA) measurements}

The dynamic mechanical analysis (DMA) was performed on a TA Q800 DMA (TA Instruments, USA). The measurements were carried out at $1 \mathrm{~Hz}$ under a heating rate of $5^{\circ} \mathrm{C} / \mathrm{min}$. The temperature range was from $-50^{\circ} \mathrm{C}$ to $170^{\circ} \mathrm{C}$. The low temperature measurements were performed in a stream of dry air cooled with liquid $\mathrm{N}_{2}$, and the high temperature tests were carried out under $\mathrm{N}_{2}$ protection.

\subsection{Flame retardant property measurement}

Cone calorimeter measurements were carried out 
with a FTT Standard Cone Calorimeter (Fire Testing Technology Ltd., U.K.) at an incident heat flux of $50 \mathrm{KW} / \mathrm{m}^{2}$ in accordance with the ISO5660 standard. The specimens were $(100 \mathrm{~mm} \times 100 \mathrm{~mm} \times$ $4 \mathrm{~mm}$ ) square plaques. The data reported here is the average of three replicated experiments. The samples which were used in the cone calorimeter analysis were then used to characterize the morphology and elements of the char layers.

\subsection{Scanning electron microscopy (SEM) and $x$ - ray photoelectron spectroscopy measurement}

The surfaces of the combustion samples of nylon 1212 and nylon 1212/OMMT nanocomposites that had been characterized in cone calorimetry were executed in a JEOL JSM 6500F scanning electron microscope (SEM) (JEOL Ltd., Japan). At the same time, the elements of the combustion samples were characterized by X-ray photoelectron spectroscopy (XPS).

\section{Result and Discussion}

The TEM micrographs of the nylon 1212/OMMT nanocomposites are shown in Figure 1, lighter areas are the nylon 1212 matrix and the dark lines are the silicate layers. Figure 1 clearly showed both exfoliated platelets and some intercalated structures. It can be seen that most of the exfoliated OMMT layers with thickness of 5-10nm were homogeneously dispersed in the nylon 1212 matrix, a few OMMT particles were intercalated by macromolecular chains of nylon 1212 and a partly exfoliated structure was formed in the nanocomposites. The OMMT aggregated together with the increasing of OMMT contents. Most of the layers are oriented normal to the sections, as well as parallel to the slow direction.

Figure 2 shows are the storage modulus (a) and dynamic loss $(\tan \delta)$ (b) as a function of temperature for the nylon 1212/OMMT nanocomposites. The storage modulus of nylon 1212/OMMT nanocomposites increased with the content of OMMT increasing below $25^{\circ} \mathrm{C}$. The increase of the storage modulus was about $40 \%$ when the OMMT content was $7 \%$. However, the storage modulus of the nylon 1212/OMMT nanocomposites were not very different above $25^{\circ} \mathrm{C}$. The increase of the nanocomposites modulus was caused by the stiffness of the OMMT layers and the constraining effect on parts of the nylon 1212 molecular chain segments. As with other polymers, adding a small amount of OMMT can improve the stiffness of the polymer ${ }^{[10,20,21]}$.
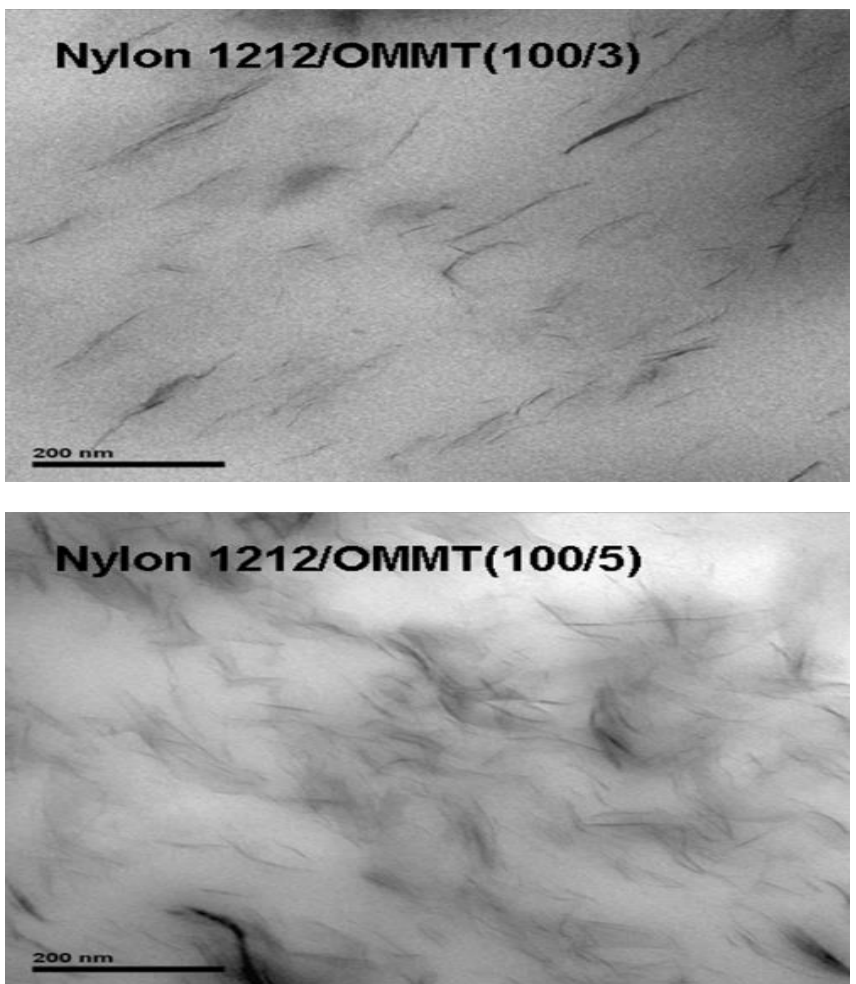

Nylon 1212/OMMT(100/7)

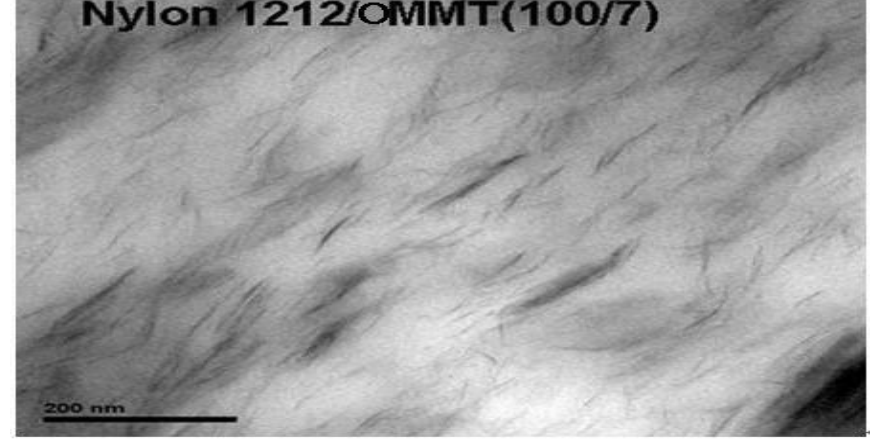

Figure 1. TEM micrographs of nylon 1212/OMMT nanocomposites containing different OMMT contents: $100 / 3,100 / 5,100 / 7$

Tg of nylon 1212 can be characterized by $\tan \delta$, Figure 2 (b) shows the $\tan \delta$ versus temperature curves for the nylon1212 and the nylon 1212/OMMT nanocomposites. For pure nylon 1212 , there was only one peak, assigned to $\mathrm{Tg}$ of nylon 1212 , at $65^{\circ} \mathrm{C}$. Generally, reinforcement by 
exfoliated MMT layers will result in the glass transition temperature $\left(\mathrm{T}_{\mathrm{g}}\right)$ of the polymer being increased slightly ${ }^{[10]}$. However, Figure. 2 (b) shows $\mathrm{T}_{\mathrm{g}}$ of nylon 1212/OMMT nanocomposites shifted to a lower temperature by about $10^{\circ} \mathrm{C}$ with increasing contents of OMMT in comparison with the corresponding peak for pure nylon 1212. This is attributed to the CDBAC, some CDBAC which was not intercalated into the galleries of MMT were being adsorbed outside of the galleries, and acting as a plasticizer during compounding of the OMMT with the nylon 1212 melt. In addition, the height of the $\tan \delta$ peak of nylon 1212/OMMT (100/7) nanocomposite decreased by about $17 \%$ in comparison with the corresponding peak for pure nylon 1212 . This indicates that a number of chain segments of nylon 1212 in the composite samples

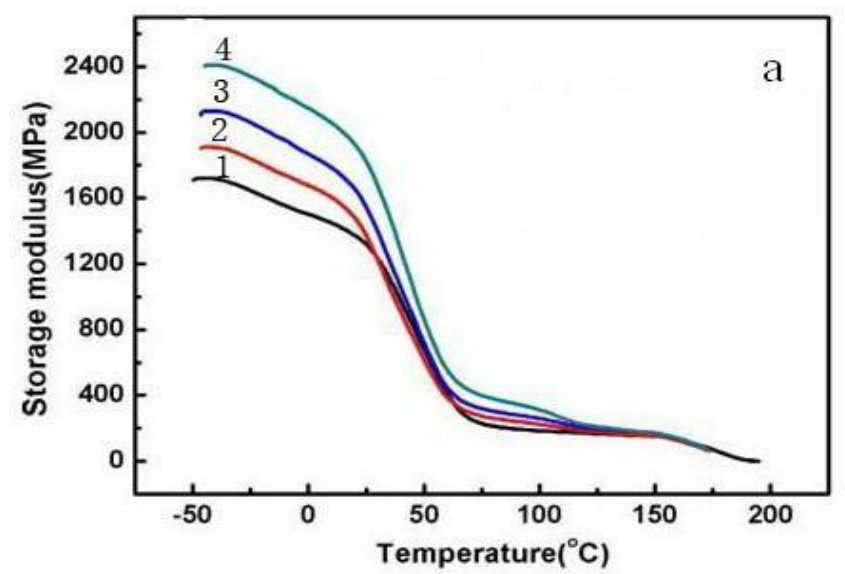

did not participate in the plasticized glass transition, because nanosized OMMT has a high specific surface area. It is reported that the constrained volume in nylon 6 nanocomposites with $5 \mathrm{wt} \%$ organic MMT was over $30 \%{ }^{[22]}$. Therefore, the mobility of some chain segments of nylon 1212 were restricted by the nanosized OMMT. A new peak was shown in Figure 2 (b) at $115^{\circ} \mathrm{C}$, as well as the fact that the phenomenon it represents was characterized by a high activation energy, indicating it was the increase in the number of restricted mobility nylon 1212 segments, which suggests that it was associated with the glass transition of some nylon 1212 chain that were restricted in mobility because of their interaction with the MMT layers.

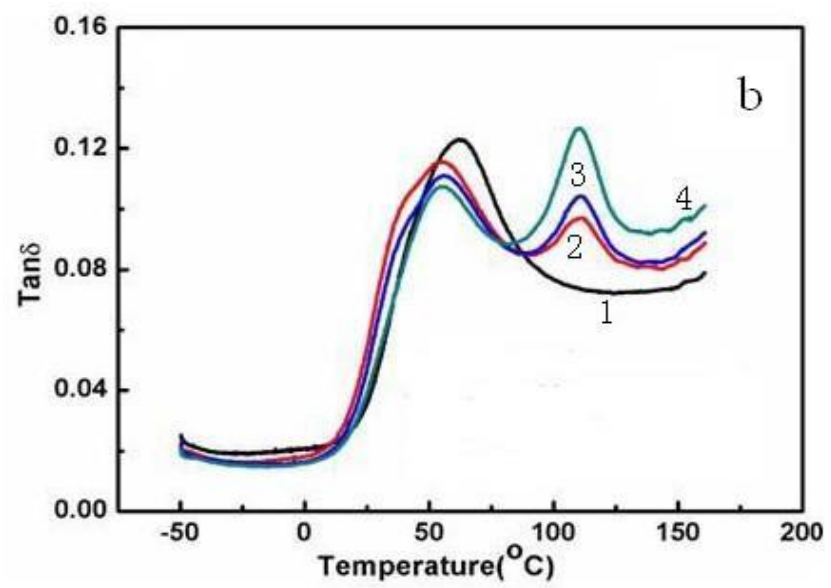

Figure 2. Plots of storage modulus (E') (a) and dynamic loss ( $\tan \delta)$ (b) as a function of temperature for nylon 1212/OMMT nanocomposites

1-PA1212/OMMT(100/0); 2-PA1212/OMMT (100/3); 3-PA1212/OMMT(100/5); 4-PA1212 / OMMT(100/7)

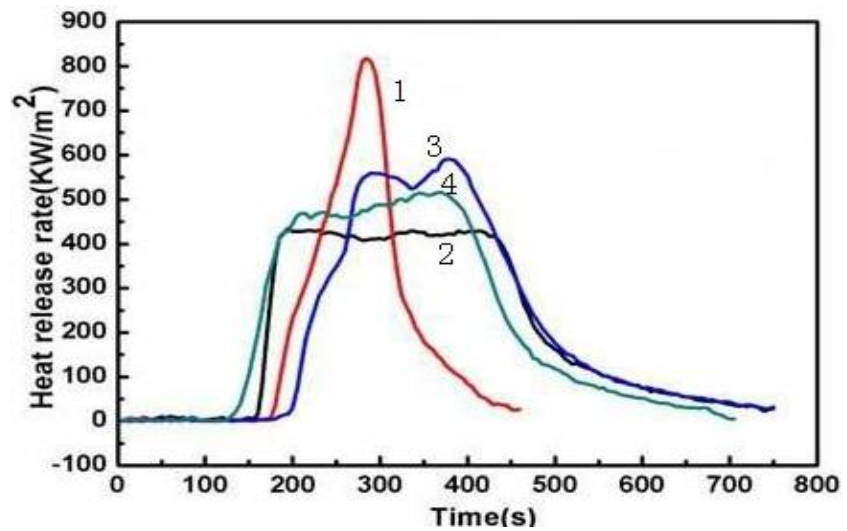

Figure 3. The HRR patterns of nylon 1212/OMMT nanocomposites

1-PA1212/OMMT(100/0); 2-PA1212/OMMT (100/3); 3-PA1212/OMMT(100/5); 4-PA1212/OMMT(100/7)

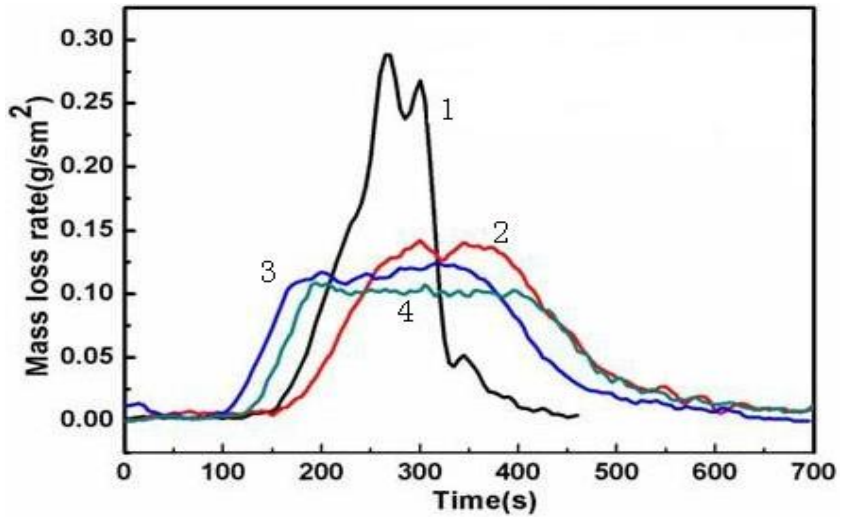

Figure 4. Mass loss rate (MLR) curves of nylon 1212/OMMT nanocomposites

1-PA1212/OMMT(100/0); 2-PA1212/OMMT(100/3); 3-PA1212/OMMT(100/5); 4-PA1212/OMMT(100/7) 
The heat release rate (HRR) and the mass loss rate (MLR) were measured by the cone calorimetry tests. HRR is used to evaluate the heat released during combustion of samples and MLR corresponds to the mass loss of samples in combustion. In particular, the peak of heat release rate (PHRR) is the most important parameter to evaluate fire safety. The HRR curves of pure nylon 1212 and nylon 1212/OMMT nanocomposites with different OMMT contents are shown in Figure 3.

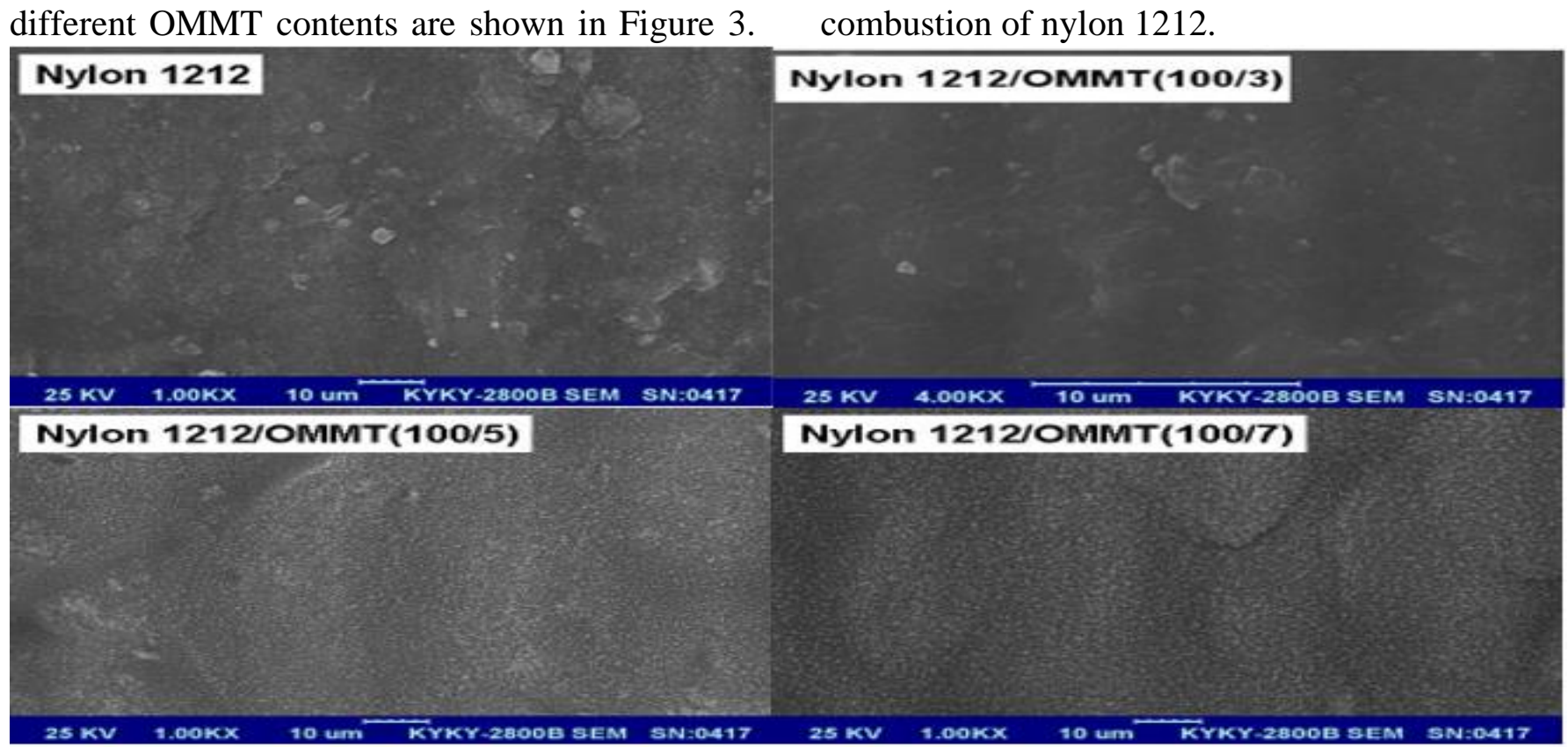

.Figure 5. SEM images of char layer of nylon 1212 and nylon 1212/OMMT nanocomposites after combustion
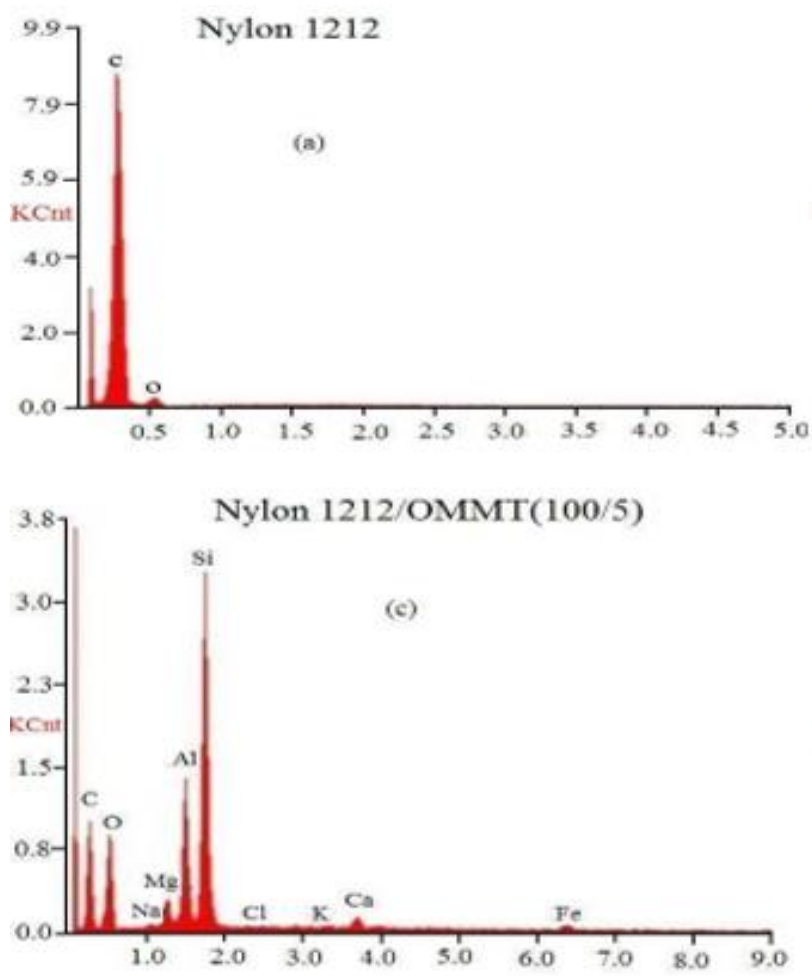

Figure 6. XPS of char layer of nylon 1212 and nylon 1212/OMMT nanocomposites after combustion
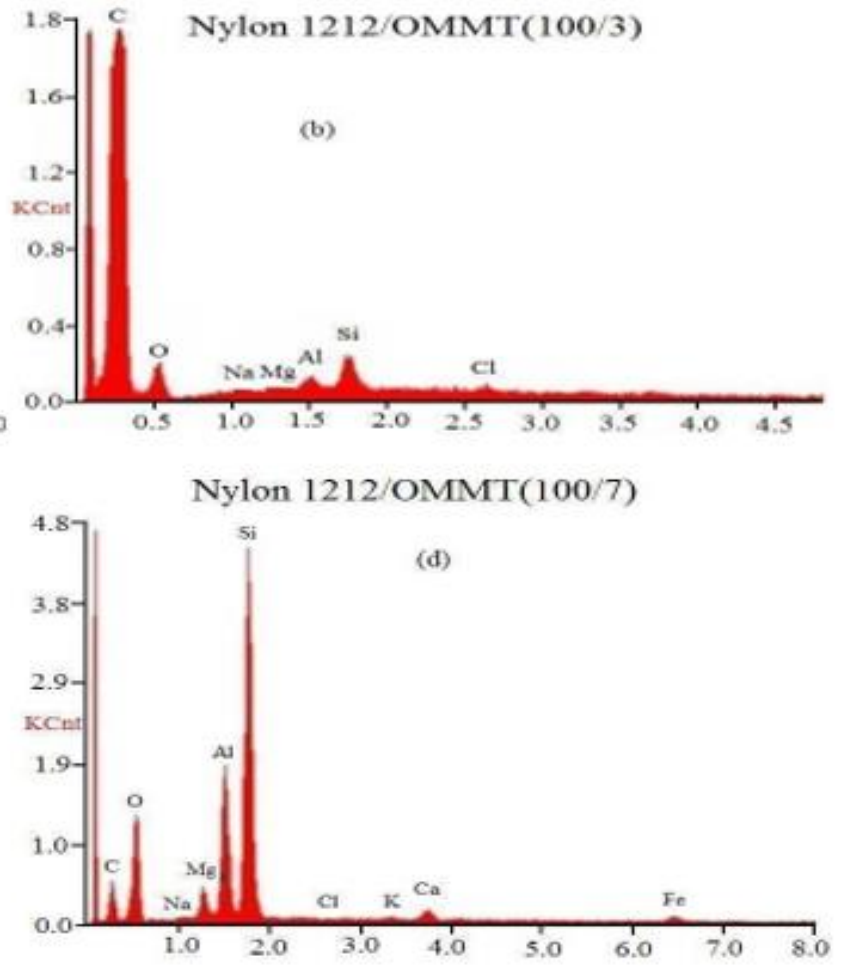

The results showed that the pure nylon 1212 burned very fast after ignition and had a sharp peak $\left(818 \mathrm{~kW} / \mathrm{m}^{2}\right)$ on the HRR curve. However, loading of OMMT into the nylon 1212 resulted in a great decline of HRR, the PHRR of nylon 1212/OMMT (100/7) was reduced by $45 \%$ compared with that of pure nylon 1212. Figure 3 also shows the HRR peak of nylon 1212/OMMT samples were broader than nylon 1212. Thus, OMTT had an effect on the combustion of nylon 1212 .

Nylon $1212 / 0 M M T(100 / 3)$

Nyion $1212 / 0$ MMT(100/7) 
Another primary parameter which is relevant to HRR is the mass loss rate (MLR) during combustion. The plots of MLR of nylon 1212 and the nylon 1212/OMMT nanocomposites are shown in Figure 4, the trend of the evolution of the MLR was the same as that of the HRR. The pure nylon 1212 reached a sharp peak on the MLR curve after ignition in a fast manner, whereas the loading of OMMT into nylon 1212 resulted in a sharp decline, but on extension of time of MLR. Thus, the decrease of HRR and MLR of nylon 1212/OMMT indicated that the amounts of heat, smoke and poisonous gas were released slower during combustion. The improvement in flame retardant properties of polymer/OMMT nanocomposites has been reported to be due to the formation of a multilayered carbonaceous-silicate structure in the condensed phase, as shown below ${ }^{[23-24]}$. The micromorphology compositions of the char layer of nylon 1212 and nylon 1212/OMMT nanocomposites were studied by SEM, as per the results shown in Figure 5. The SEM images showed that there was a change in the surface appearance with increasing OMMT contents. It was concluded that the granular materials were carbonaceoussilicate materials after the XPS analysis. The element compositions of the char layer of nylon 1212 and nylon 1212/OMMT nanocomposites were studied by XPS, the results are shown in Figure 6. The contents of silicon $(\mathrm{Si})$ were obtained by integral calculation of the peak area of the $\mathrm{Si}$ element, as $\mathrm{Si}$ increased in the char layers faster than the content of OMMT in nylon 1212 was increased, which is shown in Figure 7. Therefore, the OMMT removed to the surface of carbon contents during combustion, which will in favor a protective layer formation. This stable physical protective barrier on the surface of polymer materials is suggest to insulate the underlying polymeric substrate from the heat source, slow down heat and mass transfer between the gaseous and condensed phases ${ }^{[24]}$. The presence of OMMT created a barrier effect of the char residues formed on the surface of nylon 1212 matrix.

Therefore, these results confirm that the barrier properties of the OMMT provide a mechanism in which nanocomposites formation can enhance the flame retardancy of polymers and reduce the amount of flammable small decomposition products released during combustion.

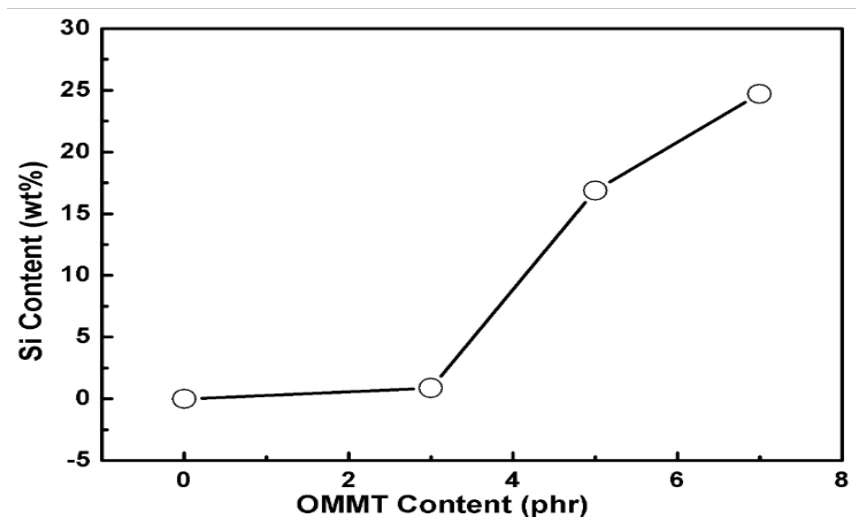

Figure 7. Si contents of the evolution with the OMMT increase of char layer of $\mathrm{f}$ nylon 1212 and nylon 1212/OMMT nanocomposites after combustion.

\section{Conclusions}

In this study, the morphology, dynamic mechanical properties and flame retardancy of nylon 1212/OMMT nanocomposites were investigated. The exfoliated OMMT layers, with thickness of 5$100 \mathrm{~nm}$ were homogeneously dispersed in the nylon 1212 matrix. The storage modulus of nylon 1212/OMMT nanocomposites increased with the increase of OMMT contents. $\mathrm{T}_{\mathrm{g}}$ of the nylon 1212/OMMT nanocomposites shifted towards a lower temperature by about $10^{\circ} \mathrm{C}$ for all of OMMT contents, in comparison with the corresponding peak for pure nylon 1212. A new peak at higher temperature was observed from plots of $\tan \delta$ as a function of temperature because the mobility of a number of chain segments of nylon 1212 were restricted by the nanosized OMMT. The flame retardant properties of the 1212/OMMT nanocomposites were improved with increasing OMMT contents.

\section{Disclosure statement}

The author declares no conflict of interest.

\section{References}

[1]Wang D, Parlow D, Qiang Y, et al., (2001), PVC-clay nanocomposites: Preparation, Thermal and Mechanical Properties[J]. Journal of Vinyl and Additive Technology, 
7(4):203-213.

[2]Usuki A, Kojima Y, Kawasumi M, et al., (1993), Synthesis of Nylon 6-Clay Hybrid[J]. Journal of Materials Research, 8(05):1179-1184.

[3]Kord B, Malekian B, Ayrilmis N, (2017), Weathering Performance of Montmorillonite/ Wood Flour-Based Polypropylene Nanocomposites[J]. Mechanics of Composite Materials, 53(5):271-278.

[4]Nan, Zhang, Ai-ling, et al., (2018), Effect of Liquid Crystal Ionomer Intercalated Montmorillonite Nanocomposites on PEO/PLA Solid Polymer Electrolytes[J]. Ionics, 16.

[5]Wang X, Li Z, Zhang M, et al., (2017), Preparation of a Polyphenylene Sulfide Membrane from a Ternary Polymer/Solvent/Non-Solvent System by Thermally Induced Phase Separation[J]. RSC Advances, 7(17):10503-10516.

[6]Follain N, Alexandre B, Chappey C, et al., (2016), Barrier Properties of Polyamide 12/Montmorillonite Nanocomposites: Effect of Clay Structure and Mixing Conditions[J]. Composites Science \& Technology, 136(18):18-28.

[7]Fornes TD, Hunter DL, Paul DR, (2004), Nylon-6 Nanocomposites from Alkylammonium-Modified Clay: The Role of Alkyl Tails on Exfoliation[J]. Macromolecules, 37(5):1793-1798.

[8]Xing S, Li R, Si J, Tang P, (2016), In situ Polymerization of Poly(Styrene-Alt-Maleic Anhydride)/Organic Montmorillonite Nanocomposites and their Ionomers as Crystallization Nucleating Agents For Poly(Ethylene Terephthalate)[J]. Journal of Industrial \& Engineering Chemistry, 38(25): 167-174.

[9]Wu Z, Zhou C, Na Z, (2002), The Nucleating Effect of Montmorillonite on Crystallization of Nylon 1212/Montmorillonite Nanocomposite[J]. Polymer Testing, 21(4):479-483.

[10]Yu ZZ, Cheng Y, Yang M, et al., (2010), Mechanical and Dynamic Mechanical Properties of Nylon 66/Montmorillonite Nanocomposites Fabricated by Melt Compounding[J]. Polymer International, 53(8):1093-1098.

[11]Priya L, Jog JP, (2003), Intercalated Poly(Vinylidene Fluoride)/Clay Nanocomposites: Structure and Properties[J]. Journal of Polymer Science Part B Polymer Physics, 41(1):31-38.

[12]Tsagaropoulos G, Eisenberg A, (1995), Dynamic Mechanical Study of the Factors Affecting the Two Glass Transition Behavior of Filled Polymers.
Similarities and Differences with Random Ionomers[J]. Macromolecules, 28(18):6067-6077.

[13]Weyand S, Blattmann H, Schimpf V, et al., (2016), Structure-Property-Glass Transition Relationships in Non-Isocyanate Polyurethanes Investigated by Dynamic Nanoindentation[J]. Materials Research Express, 3(7):075019.

[14]Jin Z, Start P, Mauritz KA, (2002), Thermal Stability and Flame Retardancy of Poly(Methyl Methacrylate)-Clay Nanocomposites[J]. Polymer Degradation \& Stability, 77(2):253-258

[15]Wang S, Yuan H, Zong R, et al., (2004), Preparation and characterization of flame retardant ABS/montmorillonite nanocomposite[J]. Applied Clay Science, 25(1-2):49-55.

[16]Kashiwagi T, Jr R, Xin Z, et al., (2004), Flame Retardant Mechanism of Polyamide 6-Clay Nanocomposites[J]. Polymer, 45(3):881-891.

[17]Song JB, Ren MQ, Chen QY, et al., (2004), Determination of Degree of Crystallinity of Nylon 1212 by Wide-angle X-ray Diffraction[J]. Chinese Journal of Polymer Science (English Edition), 22(5):491-496.

[18]Wu Z, Zhou C, Na Z, (2002), The Nucleating Effect of Montmorillonite on Crystallization of Nylon 1212/Montmorillonite Nanocomposite[J]. Polymer Testing, 21(4):479-483.

[19]Ren M, Song J, Song C, et al., (2005), Crystallization Kinetics and Morphology of Poly(Butylene Succinate-Co-Adipate)[J]. Journal of Polymer Science Part B: Polymer Physics.

[20]Agag T, Koga T, Takeichi T, (2001), Studies on Thermal and Mechanical Properties of Polyimide-Clay Nanocomposites[J]. Polymer, 42(8):3399-3408.

[21]Wang D, Parlow D, Yao Q, et al., (2010), PVC-clay Nanocomposites: Preparation, Thermal and Mechanical Properties [J]. Journal of Vinyl \& Additive Technology, 7(4):203-213.

[22]Kojima Y, Usuki A, Kawasumi M, et al., (2010), Novel Preferred Orientation in Injection-Molded Nylon 6-Clay Hybrid[J]. Journal of Polymer Science Part B Polymer Physics, 33(7)

[23]Qin H, Zhang, et al., (2005), Flame Retardant Mechanism of Polymer/Clay Nanocomposites based on Polypropylene[J]. Polymer London.

[24]Yong T, Yuan H, Lei S, et al., (2006), Preparation and Combustion Properties of Flame Retarded Polypropylene-Polyamide-6 Alloys[J]. Polymer Degradation \& Stability, 91(2):234-241 